The Journal of Experimental Biology 215, 1017-1030 (c) 2012. Published by The Company of Biologists Ltd doi:10.1242/jeb.059105

\title{
REVIEW
}

\section{Seascapes: the world of aquatic organisms as determined by their particulate natures}

\author{
George A. Jackson \\ Texas A\&M University, College Station, TX 77843, USA \\ gjackson@tamu.edu
}

Accepted 19 July 2011

\begin{abstract}
Summary
The interactions between planktonic organisms and their aquatic environment are mediated by diffusive processes on the scale of millimeters and smaller. The uptake of nutrients and food and the release of metabolic products creates localized patchiness that diffusive processes homogenize. Organism size determines, to a large extent, the character of these interactions. This paper builds a framework for considering these interactions, starting with an analysis of the diffusive environment around individual organisms and concluding with an integration over a range of organism sizes to describe aggregated properties. Several examples show the importance of the size-based abundance of organisms and other particles in determining the duration, spatial extent and frequency of environmental cues. One implication of these results is that microbial chemotactic behavior does not help them to find and utilize the majority of nutrient releases.
\end{abstract}

Key words: aquatic environments, chemotaxis, diffusion, microbial uptake, plumes.

\section{Introduction}

Planktonic organisms are particles. They are discrete objects, suspended in water; they fall or rise; they collide. They concentrate material from a dilute solution and they discharge concentrated material back to the solution. A solitary cell is but one of a mixture of particles, living and dead, small and large. Organisms and other particles structure the physical/chemical environment of the aquatic medium, either by temporarily changing solution concentrations around them or, in an analogous manner, by changing the distributions of organisms. The summed changes from all these interactions give aquatic environments a spatial texture that can be considered a seascape (Fig. 1). This seascape affects an organism's ability to respond, either feeding passively or hunting actively for prey. In all of this, size is the crucial parameter determining how an organism or other particle interacts with its environment, including other objects. While any organism can be described by a multitude of size measures, we shall use length here, unless otherwise noted.

There is a rich tradition in applied mathematics, physics and engineering describing the interactions between particles and their environments. Most fundamental to understanding how a particle interacts with its surrounding solution is molecular diffusion theory, which has been extensively developed in applied mathematics (e.g. Carslaw and Jaeger, 1959; Crank, 1975). The mathematical descriptions extend to include the role of fluid motions (e.g. Clift et al., 1978; Leal, 1992). The techniques have been applied to describe single cells and the rates at which they take up nutrients from solution (e.g. Munk and Riley, 1952; Dusenbery, 2009). Most such studies emphasize steady-state situations, but there has been interest in the effects of pulsed input (e.g. McCarthy and Goldman, 1979; Jackson, 1980; Jackson, 1987; Lehman and Scavia, 1982).

The first mathematical analysis describing how particles in a fluid interact with each other in what is now known as coagulation theory is usually attributed to Smoluchowski (Smoluchowski, 1917). To describe how particles interact with each other in a fluid, we itemize the possible mechanisms bringing them together and then describe the rates mathematically. Important properties for a particle include its mass, diameter, settling speed and, if it is alive, its mobility and sensory capabilities. Coagulation theory focuses on describing collisions arising from three mechanisms: Brownian motion, differential settling and shear. Brownian motion describes how random fluctuations in particle positions can lead to collisions; differential sedimentation describes how a particle falling faster than another particle can overtake it and collide; shear describes how turbulent water motions can cause particles to collide. These three mechanisms can be extended to describe the rates at which many organisms feed on each other.

We know organisms are also discrete particles, and we know some of their properties, including diameter, density and chemical composition. One important point is that inert particle interactions have analogs in how organisms interact with each other. Early pioneers in developing the correspondence between the two include Gerritsen and Strickler (Gerritsen and Strickler, 1977) and Fenchel (Fenchel, 1984). More recent thinking has been summarized by Kiørboe (Kiørboe, 2008) and Dusenbery (Dusenbery, 2009). Dusenbery has applied these approaches to aquatic organisms, with an emphasis on the factors that affect transport to individuals (Dusenbery, 2009).

As organisms sit or move through the environment, they leave trails, regions depleted in some substances and enhanced in others. They might be consuming oxygen, dissolved organic compounds or plant nutrients; they may be excreting carbon dioxide, ammonia or amino acids. They may be copepods leaving pheromones to attract a mate; they may be predators clearing a path of prey; or they may be aggregates falling, disintegrating while they fall, leaving a trail rich in microbial food. In time, all these trails fade back into the homogeneous background (Fig. 1). While they exist, 


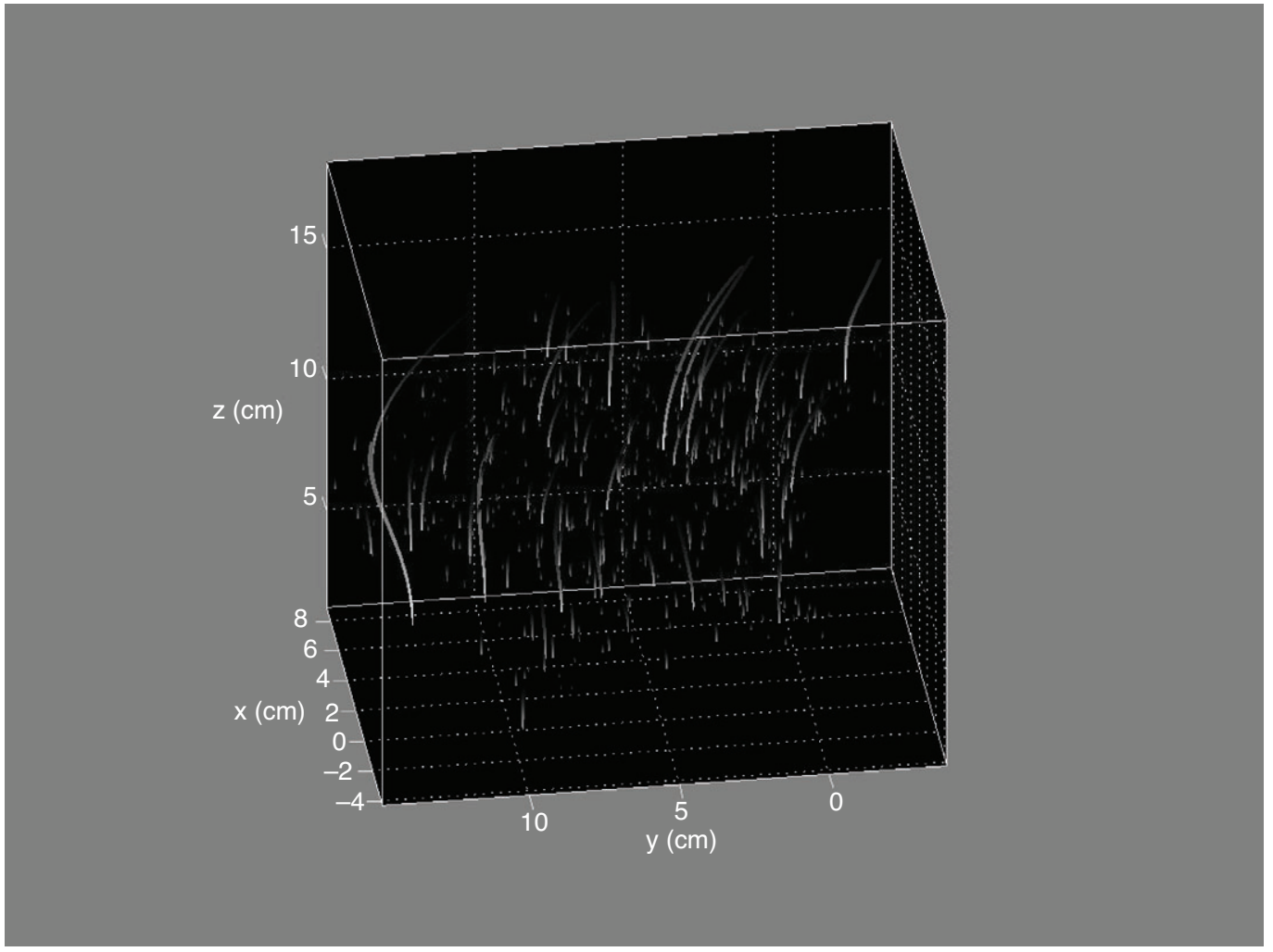

Fig. 1. Particle universe. The figure shows 500 settling particles in $1 \mathrm{l}$, ranging in diameter from 0.01 to $0.22 \mathrm{~cm}$ with a size distribution typical of what has been measured. The trails represent the expected plumes behind them. The particles are embedded in a turbulent situation, simulated as in Visser and Jackson (Visser and Jackson, 2004). The figure portrays the distribution of plume sizes that exist for a typical particle size distribution but is not meant to show the actual distribution to be expected.

they provide enhanced resources. For a bacterium looking to colonize a marine snow particle or a male copepod looking for a mate, they increase the chances of success. For a microbe looking to pull in food from the solution, they constrain growth rates. Of particular interest have been the roles that elongated trails, or plumes, behind swimming animals or falling particles can have in helping microbes overcome low nutrient concentrations. These trails provide resources whose extent and lifetime determine how well they can be exploited.

Our understanding of the nature of this environment on the organism scale is not well developed and, as a result, neither is our understanding of how organisms interact with each other. In this paper, I describe the chemical environments of individual microbes and animals; I then describe some of the implications for ecosystem function; lastly, I summarize and extend the mathematics used to describe the temporal and spatial extent of various plumes. In much of this, I emphasize marine bacteria because they are the smallest marine organisms with the simplest physical constraints and because they meet all their nutritional needs by taking in small molecules from solution. Symbols in the text are summarized in Tables 1 and 2. In some cases, the symbols and equations are introduced in the Appendix.

\section{Vignettes}

We begin the analysis with the simple bacterial cell, starting with typical values for bacterial size, abundance and environmental nutrient concentrations (Table2). We compare the bacteria to their environment, both physically and chemically. We express the chemical content of the cell in terms of nitrogen and assume that it is spherical in shape. We assume that the edge of the depletion region resulting from the cell's uptake is where the concentration reaches half the background concentration. We then examine nutrient sources, including zooplankton excretion and marine snow breakdown, and their implications.

How extensive is bacterial depletion?

For a marine bacterium with a typical radius of $0.25 \mu \mathrm{m}$, the radius of the depleted zone around it is twice its radius, $0.5 \mu \mathrm{m}$. The volume of the depleted region is $2^{3}=8$ times that of the cell ( 7 times if the cell's volume is subtracted). A typical background concentration of the dissolved organic nitrogen (DON) used by the cell is $10 \mathrm{nmoll}^{-1}$; with a nitrogen content of $1.4 \times 10^{-16} \mathrm{~mol}$ per cell, the internal bacterial $\mathrm{N}$ concentration is $2.2 \mathrm{moll}^{-1}, 2 \times 10^{8}$ greater than the background concentration. This internal content equals all the dissolved material within a distance of $146 \mu \mathrm{m}$ of the cell.

A typical bacterial abundance is $5 \times 10^{5} \mathrm{cells}^{-3}$, equivalent to a content of about $70 \mathrm{nmoll}^{-1} \mathrm{~N}$ if distributed equally through the solution. The vastly greater concentration of material within the cells than dissolved in the environment implies that bacterial uptake is relatively efficient and relies on continual resupply to sustain it. Such resupply is part of the regeneration process, in which material present as organisms or other particles is metabolized and released as small molecules available for formation of new particle mass. If the bacterial cells were to be uniformly distributed on a lattice, they would be spaced $126 \mu \mathrm{m}$ apart. Thus, the diameter of the depletion region around each bacterium $(1 \mu \mathrm{m})$ is small relative to the spacing between cells (Fig. 2). 
Table 1. Notation

\begin{tabular}{|c|c|c|c|}
\hline Symbol & Meaning & Typical values & Units \\
\hline a & Bacterial radius & $2.5 \times 10^{-5}$ & $\mathrm{~cm}$ \\
\hline$A$ & Bacterial abundance & $5 \times 10^{5}$ & $\mathrm{~cm}^{-3}$ \\
\hline$C$ & Concentration & & $\mathrm{mol} \mathrm{cm}^{-3}$ \\
\hline$C_{\mathrm{r}}$ & Reference concentration & & $\mathrm{mol} \mathrm{cm}-3$ \\
\hline$C_{0}$ & Background concentration & & $\mathrm{mol} \mathrm{cm}^{-3}$ \\
\hline$d$ & Bacterial diameter & $5 \times 10^{-5}$ & $\mathrm{~cm}$ \\
\hline$D$ & Diffusion coefficient & $10^{-5}$ & $\mathrm{~cm}^{2} \mathrm{~s}^{-1}$ \\
\hline$F$ & Flow of mass to a cell & & $\mathrm{mol} \mathrm{s}^{-1}$ \\
\hline$F_{\mathrm{p}}$ & Predator feeding rate & & $\mathrm{gs}^{-1}$, no. $\mathrm{s}^{-1}$ \\
\hline$I_{0}$ & Modified Bessel function & & \\
\hline$k$ & Average rate of concentration decrease & & $\mathrm{s}^{-1}$ \\
\hline$L$ & Emission rate/characteristic length of organism & & \\
\hline$m$ & Mass of object & & \\
\hline$M$ & Total mass released & & mol, g \\
\hline$n$ & Size distribution/number spectrum & & \\
\hline$N$ & Bacterial nitrogen content (see Table 2) & $1.4 \times 10^{-16}$ & $\mathrm{~mol}$ \\
\hline$p$ & Probability & & \\
\hline$P$ & Predator's sensory distance (disk radius) & & - \\
\hline $\mathrm{Pe}$ & Peclet number & & \\
\hline$Q$ & Animal respiration rate & & $\mu \mathrm{g} \mathrm{Cs}^{-1}$ \\
\hline$r$ & Radial distance & & $\mathrm{cm}$ \\
\hline$R$ & Search distance & & $\mathrm{cm}$ \\
\hline$R_{1 / 2}$ & Distance molecules diffuse in solution & & $\mathrm{cm}$ \\
\hline$s$ & Object size & & $\mathrm{cm}, \mathrm{g}, \mathrm{cm}^{3}$ \\
\hline Sh & Sherwood number & & - \\
\hline$t$ & Time & & $\mathrm{s}$ \\
\hline$T_{0}$ & Time plume lasts & & s \\
\hline$T_{1}$ & Time plume lasts in presence of microbes & & $\mathrm{s}$ \\
\hline$T_{2}$ & Time depletion plume lasts behind swimming disk & & s \\
\hline$T_{1 / 2}$ & Time for concentration to decrease to half normal & & $\mathrm{s}$ \\
\hline$T_{\mathrm{D}}$ & Time for cloud to dissipate & & \\
\hline$v$ & Swimming velocity/sinking velocity & & $\mathrm{cm} \mathrm{s}^{-1}$ \\
\hline$V_{0}$ & Volume with enhanced concentration around object & & $\mathrm{cm}^{3}$ \\
\hline$V_{1}$ & Volume with enhanced concentration around object in presence of uptake & & $\mathrm{cm}^{3}$ \\
\hline$V_{2}$ & Depletion volume behind swimming disk & & $\mathrm{cm}^{3}$ \\
\hline$V_{\mathrm{T}}$ & Fraction of volume with enhanced concentration from many objects & & \\
\hline$z$ & Distance behind moving object & & $\mathrm{cm}$ \\
\hline$Z_{0}$ & Plume length & & $\mathrm{cm}$ \\
\hline$Z_{1}$ & Plume length in presence of uptake & & $\mathrm{cm}$ \\
\hline$Z_{2}$ & Plume length behind swimming disk & & $\mathrm{cm}$ \\
\hline$\alpha$ & Constant in relationship $\alpha d^{\lambda}$ & & \\
\hline$\alpha_{1}$ & Constant relating organism $D$ to $d$ & 2.8 & $\mathrm{~cm}^{0.29} \mathrm{~s}^{-1}$ \\
\hline$\alpha_{2}$ & Constant relating organism $v$ to $d$ & 2.9 & $\mathrm{~s}^{-1}$ \\
\hline$\alpha_{2 s}$ & Constant relating organism $v$ to $d$, marine snow & 0.13 & $\mathrm{~cm}^{0.74} \mathrm{~s}^{-1}$ \\
\hline$\alpha_{3}$ & Constant relating organism $m$ to $d$ & $2.8 \times 10^{-5}$ & $\mathrm{~mol} \mathrm{~N} \mathrm{~cm}-2.23$ \\
\hline$\alpha_{4}$ & Constant relating distribution $n$ to $d$ & $3.28 \times 10^{-8}$ & $\mathrm{~cm}^{-0.41}$ \\
\hline$\alpha_{4 s}$ & Constant relating distribution $n$ to $d$, marine snow & $2.5 \times 10^{-5}$ & $\mathrm{~cm}^{-1}$ \\
\hline$\alpha_{5}$ & Constant relating respiration $Q$ to $d$ & $1.23 \times 10^{-11}$ & $\mathrm{~mol} \mathrm{~N} \mathrm{~s}{ }^{-1} \mathrm{~cm}^{-1.54}$ \\
\hline$\alpha_{6}$ & Constant relating excretion $L$ to $d$ & $3.6 \times 10^{-13}$ & $\mathrm{~mol} \mathrm{~N} \mathrm{~s}{ }^{-1} \mathrm{~cm}^{-1.5}$ \\
\hline$\beta$ & Feeding kernel, clearance rate & & $\mathrm{cm}^{3} \mathrm{~s}^{-1}$ \\
\hline$\beta_{\mathrm{sw}}$ & Feeding kernel for swimming predator & & $\mathrm{cm}^{3} \mathrm{~s}^{-1}$ \\
\hline$\beta_{\mathrm{amb}}$ & Feeding kernel for ambush predator & & $\mathrm{cm}^{3} \mathrm{~s}^{-1}$ \\
\hline$\gamma$ & Shear rate & & $\mathrm{s}^{-1}$ \\
\hline$\dot{\lambda}$ & Constant in relationship $\alpha d^{\lambda}$ & & - \\
\hline$\lambda_{1}$ & Constant relating organism $D$ to $d$ & 1.71 & - \\
\hline$\lambda_{2}$ & Constant relating organism $v$ to $d$, zooplankton & 1 & - \\
\hline$\lambda_{2 \mathrm{~s}}$ & Constant relating organism $v$ to $d$, marine snow & 0.26 & - \\
\hline$\lambda_{3}$ & Constant relating organism $m$ to $d$ & 2.23 & - \\
\hline$\lambda_{4}$ & Constant relating distribution $n$ to $d$ & -3.59 & - \\
\hline$\lambda_{4 \mathrm{~s}}$ & Constant relating distribution $n$ to $d$ for marine snow & -3 & - \\
\hline$\lambda_{5}$ & Constant relating respiration $Q$ to $d$ & 1.54 & - \\
\hline$\lambda_{6}$ & Constant relating excretion $L$ to $d$ & 1.5 & - \\
\hline$\Lambda$ & Leakage rate & & $\mathrm{mol} \mathrm{cm}{ }^{-3}$ \\
\hline$\rho_{0}^{*}$ & Plume radius & & $\mathrm{cm}$ \\
\hline$\rho_{1}^{*}$ & Plume radius in presence of uptake & & $\mathrm{cm}$ \\
\hline$\rho_{2}$ & Depletion plume radius behind moving disk & & $\mathrm{cm}$ \\
\hline$\sigma_{0}$ & Plume cross-sectional area & & $\mathrm{cm}^{2}$ \\
\hline$\sigma_{1}$ & Plume cross-sectional area in presence of microbes & & $\mathrm{cm}^{2}$ \\
\hline$\sigma^{+}$ & Plume detection cross-sectional area for zooplankton & - & $\mathrm{cm}^{2}$ \\
\hline$\Sigma$ & Interception cross-section & & $\mathrm{cm}^{-1}$ \\
\hline
\end{tabular}


Table 2. Typical bacterial cell properties

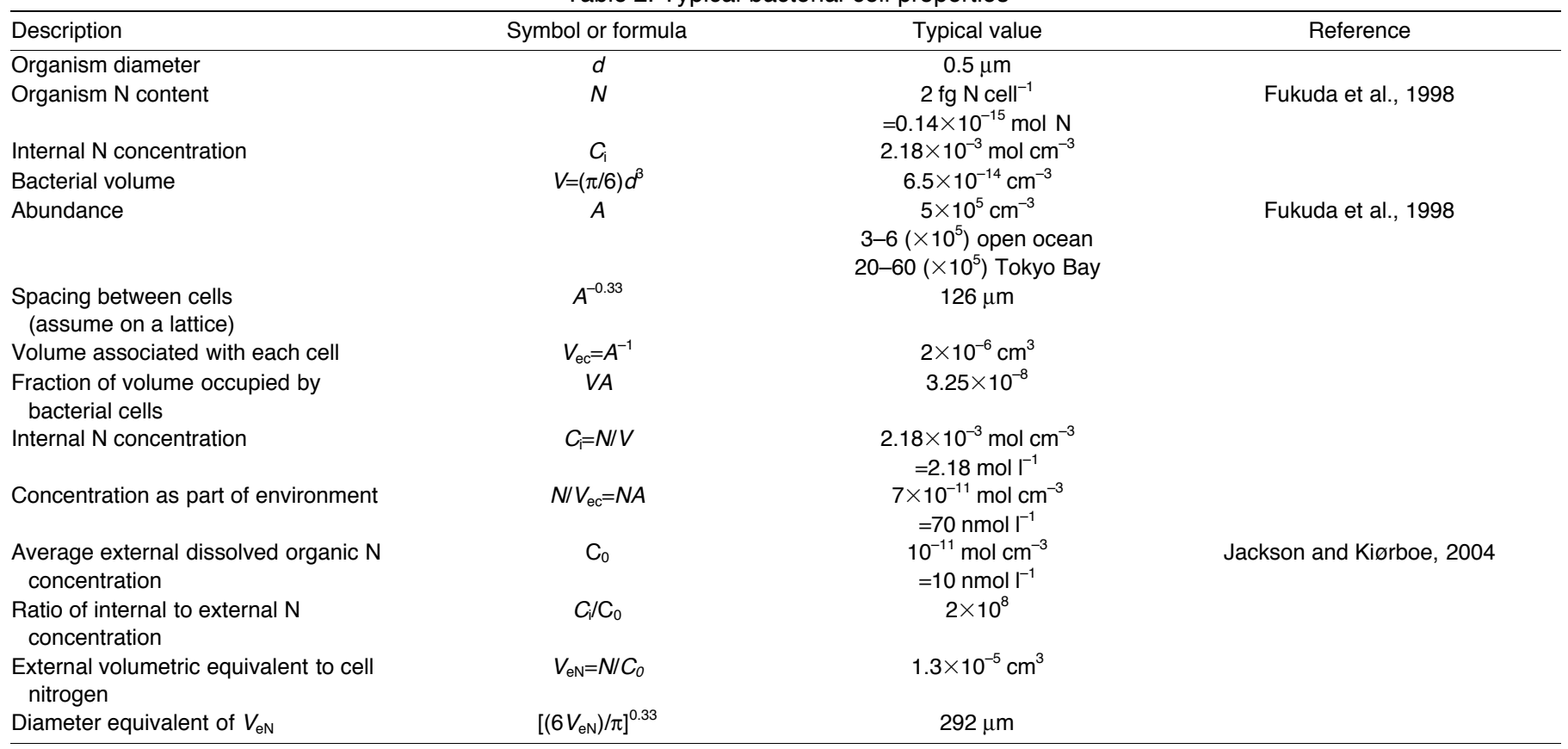

Some values are derived from observations as shown by expressions in the second column.

Examining the fate of a molecule released into solution provides a different perspective on the diffusive process. A molecule starting at a distance $r$ from a single sphere of radius $a$ has a probability of hitting the sphere equal to $a / r$ (Berg, 1983). The molecule has a better than 0.5 probability of going more than a distance of $R_{1 / 2}$ before being absorbed by cells present at an abundance $A$ (Jackson, 1987), where:

$$
R_{1 / 2}=(4 \pi A a)^{-0.5} .
$$

Stated differently, at least half of the molecules released at a given point travel further than $R_{1 / 2}$ before being absorbed by a microbe. For our typical numbers, this distance is $800 \mu \mathrm{m}$, a region that encompasses more than 1000 bacteria. The fact that this distance is far greater than the distance to the nearest bacteria, roughly no more than $126 / 2=63 \mu \mathrm{m}$, results from the small bacterial sizes relative to their spacing.

Similar calculations can be made for phytoplankton cells, but the range in cell size, geometry and abundance is much greater.

How fast does material move to bacterial cells?

For a typical molecular diffusivity of $D=10^{-5} \mathrm{~cm}^{2} \mathrm{~s}^{-1}$ and a substrate concentration that is effectively 0 , the total flow (uptake, $F$ ) into the cell can be calculated using values in Table 2 and Eqn A5 (Appendix) as $F=3.14 \times 10^{-20} \mathrm{~mol} \mathrm{~s}^{-1}=19,000$ molecules s$^{-1}$. The time to accumulate enough material to double is $T=N / F \approx 4500 \mathrm{~s}=1.25 \mathrm{~h}$, where $N$ is the amount of nitrogen in the cell. Note that these calculations assume, among other simplifications, that all molecules diffuse at the rate of a small molecule, that all molecules are useful to the cell, and that all are incorporated into particulate material.

The condition for enhancing the flux by swimming is that the Péclet number $\mathrm{Pe}=v d / D>1$, where $v$ is the swimming velocity and $d$ is the diameter (see Eqn A33 in Appendix). For a cell swimming at 20 lengths s ${ }^{-1}, v=10 \mu \mathrm{ms}^{-1}, \mathrm{Pe}=5 \times 10^{-3}$. This small value of $\mathrm{Pe}$ implies that the cell does not swim faster than diffusion can establish a gradient, so there is no enhancement of uptake and no elongated depletion plume trailing it. The absence of a depletion plume means that the immediate impact of bacterial passage is limited to a depleted spherical region that moves with it. There is little impact of its passage on the spatial structure of nutrients, except for its adding to the general bacterial consumption of material. To create a plume and leave a chemical signal of its passage, the cell would need to have $v d>D=10^{-5} \mathrm{~cm}^{2} \mathrm{~s}^{-1}$. If $v=10$ body lengths $\mathrm{s}^{-1}=10 d \mathrm{~s}^{-1}, d^{2}>10^{-6} \mathrm{~cm}^{2}$, $d>10^{-3} \mathrm{~cm}$. That is, the minimum size at which bacterial motion has any impact on creating depletion plumes or on enhancing nutrient uptake should be $\sim 10 \mu \mathrm{m}$.

The calculation of flux into a single cell does not describe the impact of a bacterial population on the general solution concentration. We can make an estimate of the rate at which material is taken up by microbes (i.e. the average rate of concentration decrease) in terms of $k$ in Eqn A11 (Appendix) if we ignore spatial structure and just sum the steady-state uptake rates of many microbes. If the rate at which bacteria take up material is set by the rate at which diffusion supplies it (the fastest rate possible), then the massed uptake rate for microbes in a diffusionlimited world is $A(2 \pi d D \Delta C)=k \Delta C$, where $\Delta C$ is the concentration difference between the bulk solution and the cell surface and:

$$
k=2 \pi d D A .
$$

For our system, $k=1.57 \times 10^{-3} \mathrm{~s}^{-1}$. For a simple system in which a pulse decreases with a constant $k$, then $\mathrm{d} C / \mathrm{d} t=-k C$ and $C / C_{\text {initial }}=e^{-k t}$. The time for the initial concentration to decrease by half is $t_{1 / 2}=1273 \mathrm{~s} \approx 21 \mathrm{~min}$. Jackson and Kiørboe (Jackson and Kiørboe, 2004) calculated the effect of bacterial uptake on typical marine snow plumes, comparing plume lengths with and without bacterial uptake (Fig. 3). When the plume shortens significantly, a significant amount of the microbial uptake occurs within the plume. One measure of this effect is when $k T_{0}>1$ (Fig. 4), where $T_{0}$ is the lifetime of the plume in the absence of uptake (Eqn A24, Appendix). For these bacterial abundances, marine snow particles need to be larger than $0.16 \mathrm{~cm}$. 


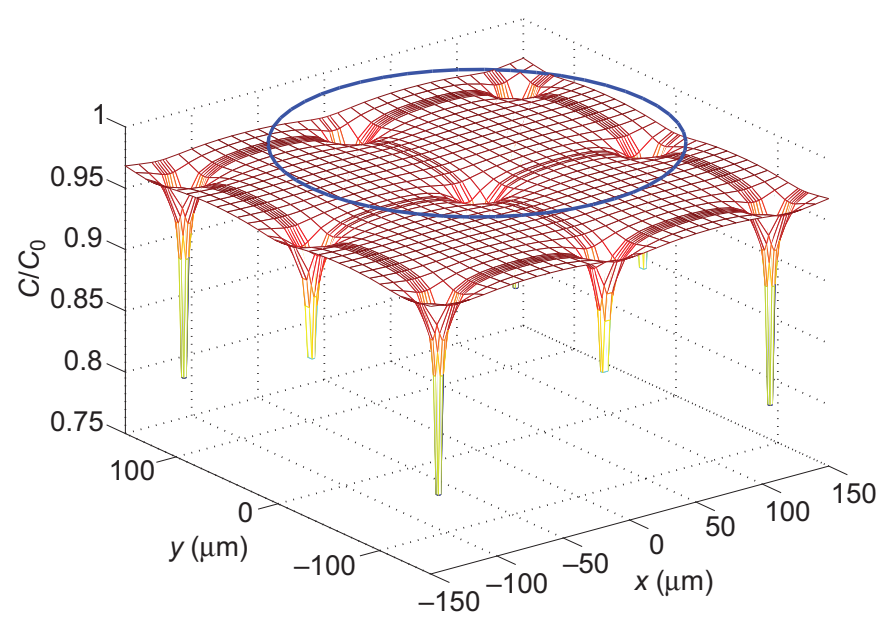

Fig. 2. Concentration around uniformly spaced bacterial cells. The bacteria are uniformly spaced on a 3-dimensional lattice. The concentrations are for a plane slicing through the lattice, containing one layer of bacteria. The blue circle in the center represents a slice through the spherical region containing the same total dissolved nitrogen as is in a cell.

A similar set of analyses can be made for phytoplankton, although the greater range of nutrient and algal concentrations, as well as organism sizes and shapes, makes any situation more complicated and less generalizable.

How big is the signal associated with lysing cells?

Blackburn and colleagues (Blackburn et al., 1998) have observed motile bacteria clustering in solution, a response that they suggest is the result of chemotactic movement to the sudden release of cellular contents. Such a release could result from cellular lysis after a viral infection. If we assume that algal carbon content ( $\mathrm{mol} / \mathrm{cell})$ is given as a function of size by $3.44 \times 10^{-5} d^{2.2}$ (Mullin et al., 1966), where $d$ is the algal radius in $\mathrm{cm}$, that the carbon to nitrogen ratio ( $\mathrm{mol} / \mathrm{mol})$ equals the 6.6 Redfield ratio, that the detectable concentration is given by $C_{\mathrm{r}}=1 \mu \mathrm{mol}{ }^{-1} \mathrm{~N}$, and that diffusivity $D$ and microbial uptake $k$ are as above, then Eqns A8, A9, A15 and A16 (Appendix) can be used to describe the characteristics of the diffusion cloud (Fig. 5). For a small, $d=1 \mu \mathrm{m}$, algal cell, the maximum radial extent of the cloud is about $400 \mu \mathrm{m}$ and the cloud disappears after $70 \mathrm{~s}$. Bacterial consumption has minimal impact on it. For 10 and $100 \mu \mathrm{m}$ algae, the clouds last almost $40 \mathrm{~min}$ and almost 1 day, in the absence of water motions or bacterial uptake. Bacterial uptake significantly decreases these times to about 15 and $52 \mathrm{~min}$. A significant increase in bacterial abundance resulting from chemotactic attraction would further decrease these times. One conclusion is that cell lysis could provide ephemeral patches lasting between $1 \mathrm{~min}$ and $1 \mathrm{~h}$, depending on the size of the cell being lysed. The estimated times are probably high because they assume that all cellular material is solubilized instantly.

\section{Do zooplankton distributions follow the same diffusion} mathematics for a region that is depleted?

Benoit-Bird (Benoit-Bird, 2009) found zooplankton layers $0.2-4.6 \mathrm{~m}$ thick in Monterey Bay, along the coast of California. The sonar technique she used documented holes of the order of $0.5 \mathrm{~m}^{2}$ created when fish passed through one of the layers. These holes took $300-400 \mathrm{~s}$ to fill back up. The layer was dominated by 0.9-1.4 mm long copepods (Calanus, Ctenocalanus, Acartia). This provides a highly visible example of a depletion plume caused by a swimming predator.
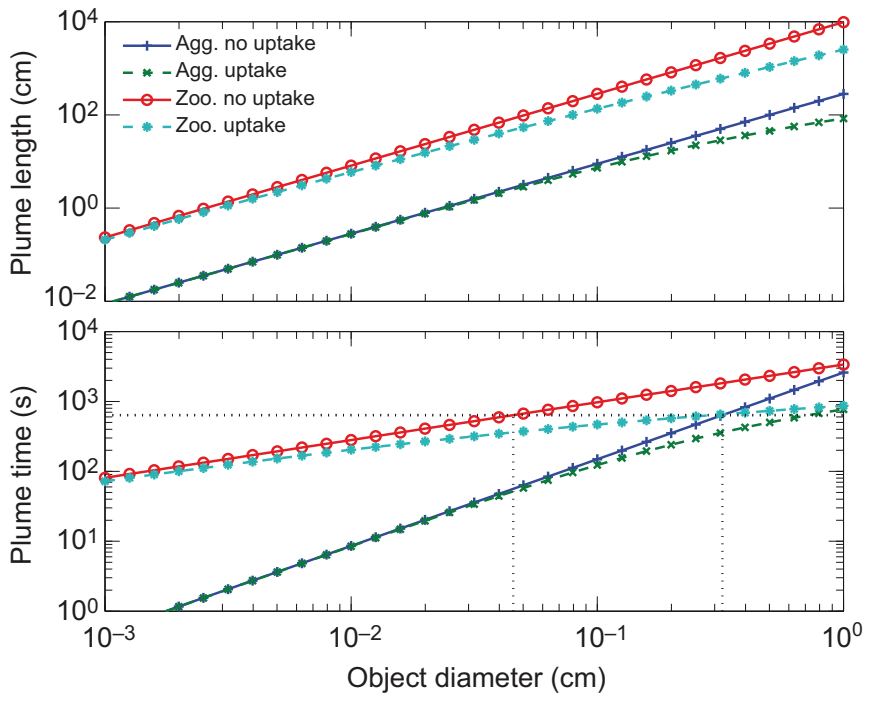

Fig. 3. Plume length $Z_{0}$ (top) and lifetime $T_{0}$ (bottom) with and without microbial uptake. The figure shows situations for zooplankton and aggregates having characteristics given in the text. As the particles get larger, the plume gets longer and the bacteria are able to compete with diffusion in determining the plume length. The horizontal dotted line in the lower panel corresponds to $k T_{0}=1$ for $k=1.57 \times 10^{-3} \mathrm{~s}^{-1}$, where $k$ is the bacterial uptake rate constant $\left(\mathrm{s}^{-1}\right)$. The diameters associated with $k T_{0}=1$ are $0.32 \mathrm{~cm}$ for the aggregates and $0.046 \mathrm{~cm}$ for the zooplankton. [Jackson and Kiørboe (Jackson and Kiørboe, 2004) mentioned a reference concentration value of $C_{\mathrm{r}}=10^{-9} \mathrm{~mol} \mathrm{~cm}^{-3}$ in the text, but actually used a value of $C_{\mathrm{r}}=10^{-11} \mathrm{~mol} \mathrm{~cm}^{-3}$ to make the calculations for their figures.]

To test the model (EqnA31, Appendix), we can use Eqn A35 to estimate an effective copepod diffusivity, $D=2.8(0.1)^{1.81}=0.05 \mathrm{~cm}^{2} \mathrm{~s}^{-1}$. This value is low compared with the estimate of $D=0.036 \mathrm{~cm}^{2} \mathrm{~s}^{-1}$ for $d=0.75 \mathrm{~mm}$ Temora longicornis and $D=0.36 \mathrm{~cm}^{2} \mathrm{~s}^{-1}$ for $d=1.9 \mathrm{~mm}$ Calanus helgolandicus (Visser and Kiørboe, 2006).

Using Eqn A31, assuming that $R=\left(0.5 \mathrm{~m}^{2}\right)^{1 / 2} / 2=35 \mathrm{~cm}$, and using $D$ for $C$. helgolandicus, we calculate the time for the copepod concentration to return to half the original concentration as:

$$
T_{1 / 2}=\frac{(35 \mathrm{~cm})^{2}}{4 D \ln 2}=20 \mathrm{~min} .
$$

This estimate is $3-4$ times higher than that calculated by Benoit-Bird but within an order of magnitude of her value. There are several important uncertainties associated with this calculation, including at what copepod concentration the hole was considered to be filled.

\section{How big are nutrient sources?}

The dominant size range where regeneration occurs depends on the size distributions of the animals and aggregates doing the release. While larger objects excrete faster, there are fewer of them. We can examine the importance of size by integrating over the appropriate size ranges.

\section{Regeneration by animals}

Respiration provides a means to estimate animal excretion through the use of stoichiometric relationships for size distribution $n$ and respiration rate $Q$. The respiration distribution as a function of size is given by $n(d) Q(d)=\alpha_{4} \alpha_{5} d^{\lambda 4+\lambda 5_{5}} d^{-2.4}$ for the combined $0-20 \mathrm{~m}$ data of Rodriguez and Mullin (Rodriguez and Mullin, 1986) and $20^{\circ} \mathrm{C}$ relationship of Huntley and Boyd (Huntley and Boyd, 1984). 


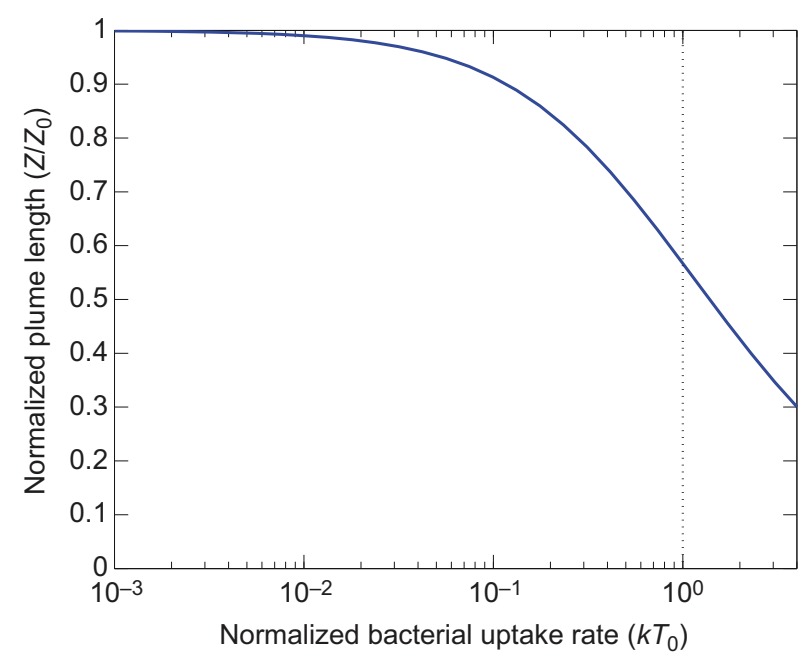

Fig. 4. Normalized effect of bacterial uptake on normalized plume length. As the bacterial uptake rate multiplied by the plume lifetime increases, bacterial uptake has a greater effect on plume length. The major change occurs around $k T_{0} \approx 1$, indicated with a vertical dotted line. $k$ is the bacterial uptake rate constant $\left(\mathrm{s}^{-1}\right)$. $T_{0}$ is the time the plume lasts in the absence of bacteria.

These values imply that regeneration is greatest at the smallest scales. The total respiration occurring in a given size range can be calculated by integrating the size-based contributions between lower and upper diameters $d_{1}$ and $d_{\mathrm{u}}$ :

$$
\begin{aligned}
\text { Total regeneration } & =\int_{d_{1}}^{d_{\mathrm{u}}} n(d) Q(d) \mathrm{d} d \\
& =\frac{\alpha_{4} \alpha_{5}}{\lambda_{4}+\lambda_{5}+1} d_{1}^{\lambda_{4}+\lambda_{5}+1}\left(1-\left(\frac{d_{1}}{d_{\mathrm{u}}}\right)^{-\left(\lambda_{4}+\lambda_{5}+1\right)}\right) \\
& \approx d_{1}^{-1.4}\left(1-\left(\frac{d_{1}}{d_{\mathrm{u}}}\right)^{1.4}\right)
\end{aligned}
$$

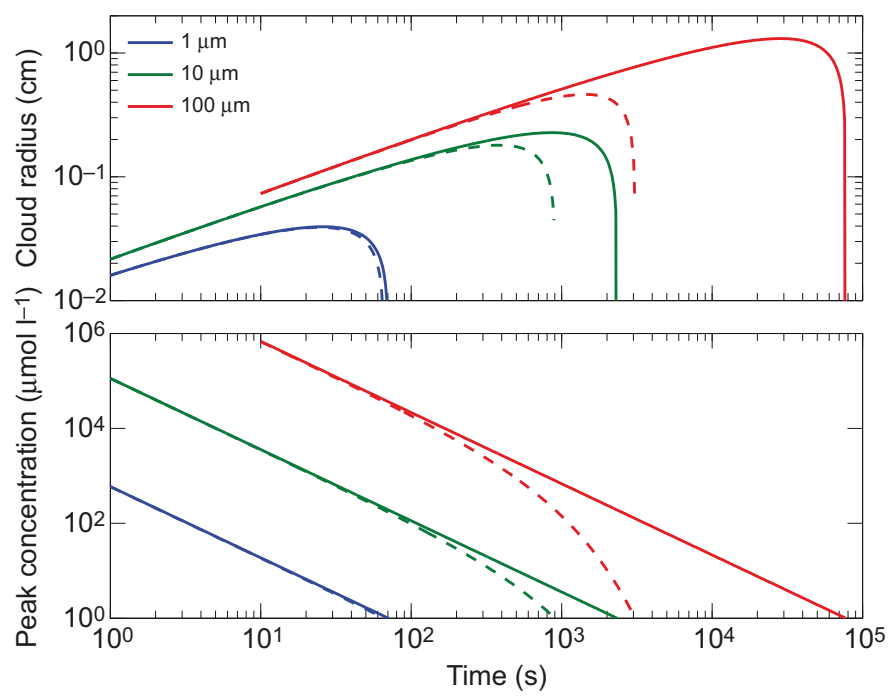

Fig. 5. Patch radius (top) and maximum concentration (bottom) associated with an algal cell disintegrating instantaneously, as a function of the algal diameter $(d=1,10,100 \mu \mathrm{m})$. Solid lines indicate the absence of microbial uptake; dashed lines indicate the presence of microbial uptake.
Most regeneration occurs at the small animal scales, presumably with the few micrometer-sized flagellates (Fig. 6). Increasing the size range of animals covered by increasing $d_{\mathrm{u}}$ has a decreasing effect on the total regeneration. More than $99 \%$ of the regeneration is from animals too small to have plumes changed by the bacterial populations (Fig. 3).

\section{Regeneration by aggregates}

Jackson and Kiørboe (Jackson and Kiørboe, 2004) used relationships for substrate leakage $\Lambda=\alpha_{6} d^{\lambda_{6}}$ and sinking velocity $v$ for marine snow $\left(\alpha_{2 \mathrm{~s}}=0.13 \mathrm{~cm}^{0.74} \mathrm{~s}^{-1}, \lambda_{2 \mathrm{~s}}=0.26, \alpha_{6}=3.6 \times 10^{-13} \mathrm{~mol} \mathrm{~N} \mathrm{~s}^{-1} \mathrm{~cm}^{-1.5}\right.$, $\left.\lambda_{6}=1.5\right)$. They also used values of $n$ measured for marine snow in Monterey Bay, California $\left(\alpha_{4 \mathrm{~s}}=2.5 \times 10^{-5} \mathrm{~cm}^{-1}, \lambda_{4 \mathrm{~s}}=-3\right)$ :

$$
\begin{aligned}
\text { Total regeneration of marine snow } & =\int_{d_{1}}^{d_{\mathrm{u}}} n(d) \Lambda(d) \mathrm{d} d \\
& =\frac{\alpha_{4} \alpha_{6}}{\lambda_{4}+\lambda_{6}+1} d_{1}^{\lambda_{4 \mathrm{~s}}+\lambda_{6}+1} \\
& \left(1-\left(\frac{d_{1}}{d_{\mathrm{u}}}\right)^{-\left(\lambda_{4 \mathrm{~s}}+\lambda_{6}+1\right)}\right) \\
& \sim d_{1}^{-0.5}\left(1-\left(\frac{d_{1}}{d_{\mathrm{u}}}\right)^{0.5}\right) .
\end{aligned}
$$

Again, most of the regeneration in the marine snow occurs in the smaller particles. However, a relatively greater fraction of particle regeneration is associated with the larger particles than the fraction of animal release associated with the larger animals (Fig.6). Microbial uptake in plumes is too small to affect the fate of most releases.

\section{Comparison}

How important is microbial consumption of the material in the plume? In Fig. 3, we argued that microbial uptake has an important impact on plume dissipation when the zooplankton forming them are larger than $0.46 \mathrm{~mm}$ long or the aggregates are larger than $3.2 \mathrm{~mm}$. The regeneration from either aggregates or animals at least this large is extremely small, $5.6 \%$ and $0.5 \%$ (Fig. 6). We conclude that microbial consumption localized within plumes is a relatively small fraction of the total consumption.

The total regeneration for both zooplankton and marine snow can be calculated by letting $d_{\mathrm{u}} \rightarrow \infty$. Assuming that $d_{1}=10 \mu \mathrm{m}$, the regeneration rate from the animals calculated here is $5.4 \times 10^{-16} \mathrm{~mol} \mathrm{~N} \mathrm{~cm}^{-3} \mathrm{~s}^{-1}$ and that for the marine snow is $5.7 \times 10^{-16} \mathrm{~mol} \mathrm{~N} \mathrm{~cm}^{-3} \mathrm{~s}^{-1}$. The two numbers are remarkably close, especially considering the arbitrary pairing of data sets, one from the oligotrophic central North Pacific and the other from nutrient-rich Monterey Bay.

Several factors could change these relationships. Microbial consumption within the plume would be relatively greater if bacterial abundance were greater or if chemotactic responses allowed bacteria to aggregate before a plume dissipated. If their uptake rates were not diffusion limited, however, they would have smaller impacts on the plumes than calculated. In any case, experimental measurements are needed to resolve these issues.

How much volume do plumes occupy?

One of the basic questions when considering plumes is just how extensive are they? Are the plumes formed by small or large objects? Again, we can use the size distribution in conjunction with the size-dependent plume volume to answer these questions. 


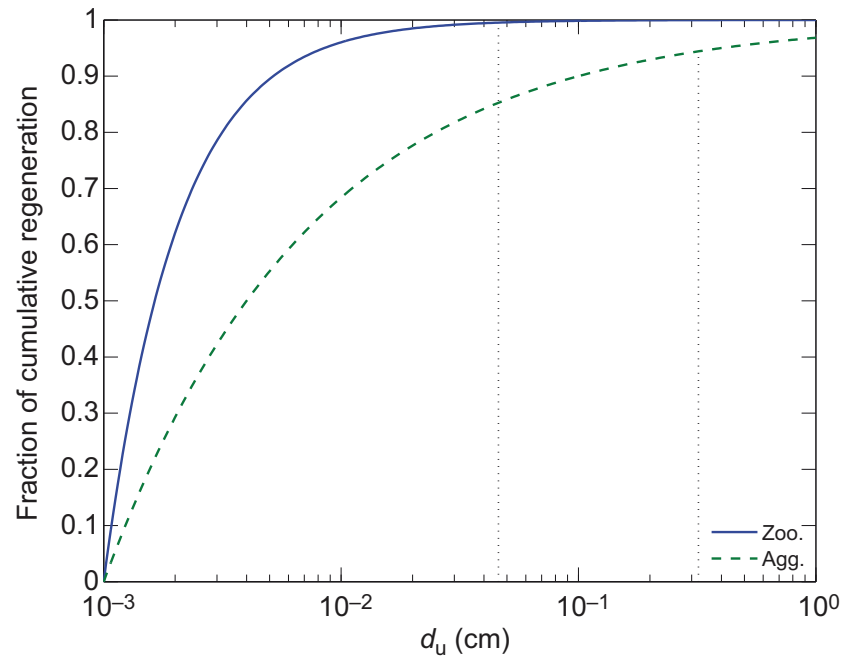

Fig. 6. The regeneration by zooplankton and aggregates between $10 \mu \mathrm{m}$ and upper diameter $d_{\mathrm{u}}$ relative to the totals for animals/particles between $10 \mu \mathrm{m}$ and $1 \mathrm{~cm}$. Solid line: zooplankton; dashed line: aggregates. The dotted lines indicate the diameters at which microbial uptake becomes a significant factor in the plume dissipation. For the zooplankton, $99.5 \%$ of the release is from animals smaller than this diameter; for the aggregates, $94.44 \%$ is released from smaller particles.

\section{From animal sources}

If we equate respiration and leakage rates $(Q=\Lambda)$ and use Eqns A36, A47 and A48 (Appendix) for $v, n$ and $Q$ for zooplankton, the volume of the plume around a single organism should be:

$$
V_{0}(d)=\frac{\alpha_{5}^{2} d^{2 \lambda_{5}-\lambda_{2}}}{\alpha_{2}\left(16 \pi C_{\mathrm{r}}^{2} D\right)} \sim d^{2.08}
$$

where ' $\sim$ ' indicates proportional to. The total volume of enhanced concentration water is then:

$$
\begin{aligned}
V_{\mathrm{T}}= & \int_{d_{\mathrm{l}}}^{d_{\mathrm{u}}} V_{0}(d) n(d) \mathrm{d} d \\
= & \frac{\alpha_{5}^{2} \alpha_{4}}{\alpha_{2}\left(16 \pi C_{\mathrm{r}}^{2} D\right)\left(2 \lambda_{5}+\lambda_{4}-\lambda_{2}+1\right)} \\
& \left(d_{\mathrm{u}}^{2 \lambda_{5}+\lambda_{4}-\lambda_{2}+1}-d_{1}^{2 \lambda_{5}+\lambda_{4}-\lambda_{2}+1}\right) \sim d_{1}^{-0.51}\left(1-\left(\frac{d_{1}}{d_{\mathrm{u}}}\right)^{0.51}\right) .
\end{aligned}
$$

Most of the plume bits are formed behind smaller animals and are, consequently, shorter lived than those behind the larger animals (Fig. 7).

\section{From aggregate sources}

While particle size distributions do not necessarily follow simple power law distributions, such distributions are useful tools in investigating the implications of size and concentration.

Again, the volume of the plume behind an individual aggregate is:

$$
V_{0}(d)=\frac{\alpha_{6}^{2} d^{2 \lambda_{6}-\lambda_{2}}}{\alpha_{2}\left(16 \pi C_{\mathrm{r}}^{2} D\right)} \sim d^{2.64} .
$$

Then, the total volume would be:

$$
V_{\mathrm{T}}=\int_{0}^{\infty} V_{0}(d) n(d) \mathrm{d} d \sim d_{1}^{0.74}\left(\left(\frac{d_{1}}{d_{\mathrm{u}}}\right)^{-0.74}-1\right) .
$$

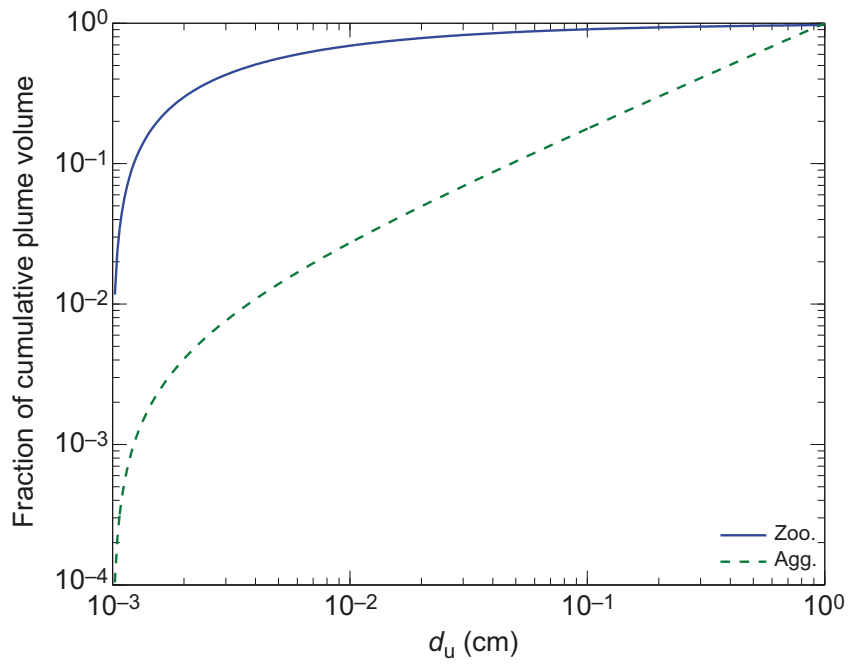

Fig. 7. The total plume volume associated with zooplankton and aggregates between $10 \mu \mathrm{m}$ and upper diameter $d_{\mathrm{u}}$ relative to the totals generated by all animals/particles between $10 \mu \mathrm{m}$ and $1 \mathrm{~cm}$. Solid line: zooplankton; dashed line: aggregates.

In this case, most of the plume volume is associated with the largest particles (Fig. 7).

\section{Comparison}

For $C_{\mathrm{r}}=1 \mu \mathrm{moll}^{-1}$, the fraction of a volume occupied by plumes is $2.0 \times 10^{-7}$ for those formed by zooplankton and $1.2 \times 10^{-8}$ for those formed by aggregates. These values are equivalent to 200 and $12 \mathrm{~mm}^{3} \mathrm{~m}^{-3}$, respectively, and represent upper estimates, as they do not include shrinkage resulting from bacterial uptake within the plumes. As noted above, such shrinkage is greater for larger plumes.

\section{How big a target are plumes for a swimmer?}

If an organism were swimming in a straight line, what would be its chances of hitting a plume? How long a time or a distance would it take? This is a problem in using the cross-sectional areas calculated in Eqns A23 and A39 (Appendix). The probability of striking any plume per unit of swimming distance depends on the concentrations of plume-forming objects, their sizes, and the crosssectional areas of their plumes. The total contribution from plumeforming objects between $d_{1}$ and $d_{\mathrm{u}}$ is:

$$
\Sigma=\int_{d_{1}}^{d_{\mathrm{u}}} \sigma n \mathrm{~d} d
$$

where $\sigma$ is the cross-sectional area of a plume, $n$ is the number spectrum and $\Sigma$ is the total cross-sectional area per unit volume. The probability of a swimmer striking plume $p$ after swimming a distance $x$ is then:

$$
p=1-e^{-\Sigma x},
$$

The value of $x=\Sigma^{-1}$ is a measure of how far an organism has to swim to find a plume. The cross-sectional areas $\sigma_{0}$ and $\sigma^{+}$derived in Eqns A23 and A39 are for an organism swimming perpendicular to a plume and represent the maximum plume exposure. Using them in place of $\sigma$ above provides an upper bound on the value of $\Sigma$. 
From animal sources

Using the power fit relationships for animal leakage rates and number spectra yields the relationship:

$$
\begin{aligned}
\Sigma & =(3 \pi D)^{-1}\left(6 \alpha_{2}\right)^{-0.5} C_{\mathrm{r}}^{-1.5} \alpha_{5}^{1.5} \alpha_{4} \int_{d_{1}}^{d_{\mathrm{u}}} d^{\lambda_{4}} d^{1.5 \lambda_{5}} d^{-0.5 \lambda_{2}} \mathrm{~d} d \\
& \sim d_{1}^{-1.78}\left(1-\left(\frac{d_{\mathrm{u}}}{d_{1}}\right)^{-1.78}\right) .
\end{aligned}
$$

The smaller animals are responsible for most of the targets (Fig. 8). For plumes produced by animals smaller than $1 \mathrm{~cm}$, $\Sigma=3.2 \times 10^{-5} \mathrm{~cm}^{-1}$.

\section{From aggregate sources}

Using the power fit relationships for aggregate leakage rates and number spectra yields the relationship:

$$
\begin{aligned}
& \Sigma=(3 \pi D)^{-1}\left(6 \alpha_{2 \mathrm{~s}}\right)^{-0.5} C_{\mathrm{r}}^{-1.5} \alpha_{6}^{1.5} \alpha_{4 s} \int_{d_{l}}^{d_{\mathrm{u}}} d^{\lambda_{4} \mathrm{~s}} d^{1.5 \lambda_{6}} d^{-0.5 \lambda_{2 \mathrm{~s}} \mathrm{~s} d} \\
& \sim d_{1}^{-0.88}\left(1-\left(\frac{d_{\mathrm{u}}}{d_{1}}\right)^{-0.88}\right) .
\end{aligned}
$$

In this case, larger aggregates provide the largest fraction of the targets (Fig. 8). For aggregates smaller than $1 \mathrm{~cm}, \Sigma=9.6 \times 10^{-6} \mathrm{~cm}^{-1}$.

\section{Comparison}

The integrated cross-sections for both zooplankton and aggregate plumes are quite small. Using $1 / \Sigma$ to calculate a characteristic distance that an organism would need to swim to find a plume, the distances are 315 and $1000 \mathrm{~m}$. An animal sensing a plume over a finite sensory distance could dramatically increase the contact rate (Jackson and Kiørboe, 2004). Alternatively, a bacterium could be in the path of a falling aggregate and have more frequent contacts (Kiørboe and Jackson, 2001).

What is the effect of mismatches between uptake and release? When the diffusivity of the incoming food and outgoing metabolic property are the same, a depleting plume and an

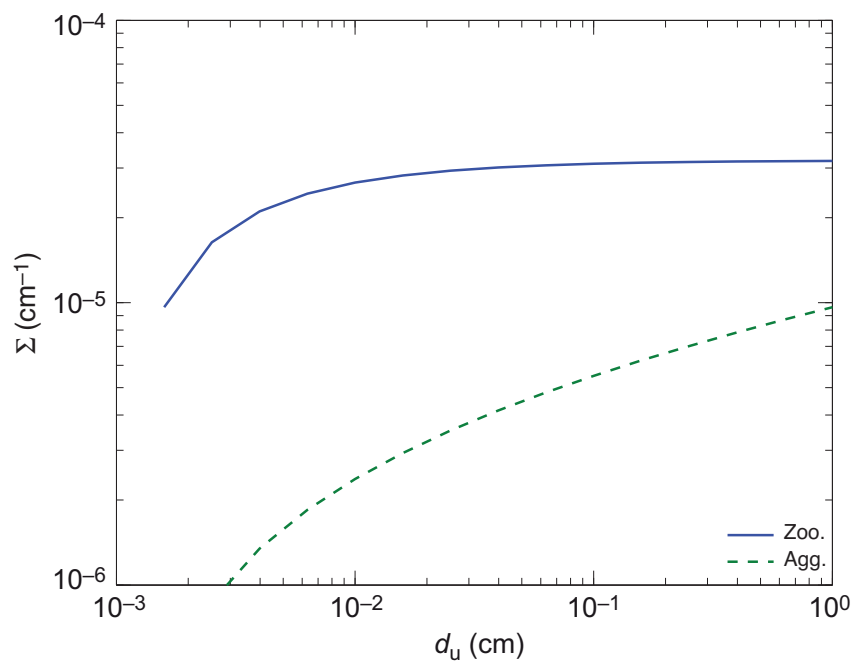

Fig. 8. The cross-sectional area $\Sigma$ presented by plumes from aggregates (dashed line) and zooplankton (solid line) between $10 \mu \mathrm{m}$ and upper diameter $d_{\mathrm{u}}$. The values of $\Sigma$ for particles $1 \mathrm{~cm}$ and smaller are $3.2 \times 10^{-5}$ and $1.0 \times 10^{-6} \mathrm{~cm}^{-1}$ for the zooplankton and the aggregates, respectively. excretion plume are similar and balance each other out (Fig.9). This can occur when the diffusivity of diffusing prey and the regenerated nutrients are the same. In particular, the diffusivities associated with swimming bacteria are similar to those of small molecules. As a result, bacterivores such as diffusive-feeding radiolarians or swimming flagellates would make smaller changes to the total $\mathrm{N}$ concentration than would an animal feeding on larger prey.

\section{Discussion}

The chemical and particle seascape is a balance between the organisms that texturize it and the diffusive and mixing processes that homogenize it. Understanding organism behavior requires a way to incorporate a range of scales into the description. Using organism size distributions in conjunction with size-based effects provides a means to do this.

The above calculations show that the bulk of nutrient release is from sources too small to be decreased by microbes before the plumes dissipate into the general background. Microbial concentrations would have to be greatly increased by chemotactic microbes in ways that we can calculate if significant amounts of the material were to be consumed in the plume. Consumption of nutrients from the diffuse background is more efficiently done by small, nonmotile cells. A system in which non-motile microbes dominate chemical uptake would be consistent with observations by B. Ward (personal communication), who noted that microbial populations in the ocean are dominated by groups with no known motility.

\section{Expanding the scope of calculations}

Behavior is difficult to incorporate into these models. There have been efforts to put chemotactic behavior into an analytical framework (e.g. Bearon and Grünbaum, 2008), but most work has involved simulations of individual microbial motions. However, simulations can be used to derive size-specific properties. For example, Kiørboe and Jackson simulated the rates of attachment of both chemotactic and non-chemotactic bacteria to falling particles of different sizes (Kiørboe and Jackson, 2001). The simulations

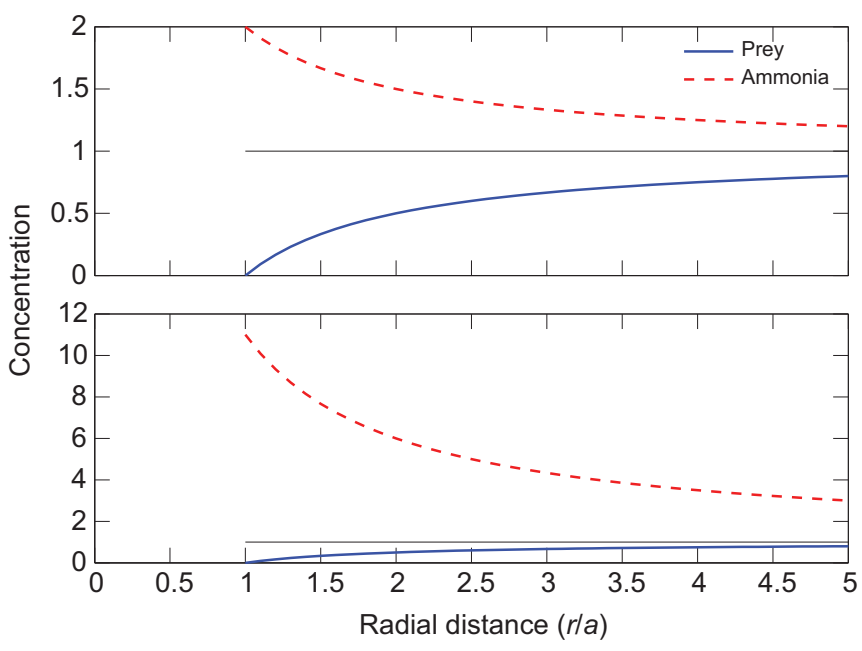

Fig. 9. Asymmetry between inbound and outbound concentration. The relative size of enhanced and depleted regions depends on the differences in flux of the released and consumed materials, which are proportional to diffusivities and concentration differences. Top: nutrient and prey have the same value of $D$ (diffusion coefficient). Bottom: nutrient and prey have different values of $D$. Note that the cell surface is at $r / a=1$, where $r$ is radial distance and $a$ is bacterial radius. 
allowed them to describe colonization rates in terms of power law relationships. Such relationships are the basis for the calculations performed above.

The various parameter values given here are not constant in the ocean, varying in time and space as well as by taxa. Because organism and aggregation concentrations vary spatially and seasonally, calculations that are location specific are needed to describe each situation. In addition, size distributions do not always fit Eqn A47 (Appendix) exactly. Using simple power laws can miss important differences in the distributions (e.g. Jackson and Checkley, 2011). More complicated distributions can always be used to make numerical integrations of the various observed system properties, such as the particle size distributions.

In these analyses, we have neglected the chemical nature of the plumes, assuming that simply calculating nitrogen concentration is sufficient. In fact, they are made of many compounds of different desirabilities, detectabilities and affinities. Describing the fates of compounds with properties, including concentrations, would strengthen the results.

Appreciating the role of turbulence is always important, particularly when larger organisms are considered, as the role of shear and organism contacts can dominate as the length scale of the interactions increases (Rothschild and Osborne, 1988; Saiz and Kiørboe, 1995). There are promising approaches to parameterizing the patchiness of larger plumes in the presence of turbulence (e.g. Visser and Jackson, 2004), but further work is needed if the approach developed here is to be extended to larger organisms and scales.

\section{Last thoughts}

Aquatic organisms exist in an environment that is heavily textured with chemical resources and cues. The production and consumption of chemical substances occurs on a range of spatial and temporal scales, which are constrained by the physics of their movement. The result is a heterogeneous environment (Fig. 1) that we must understand if we are to understand how the organisms interact.

\section{Appendix}

\section{Mathematical basics}

The movement of molecules to and from an organism in solution is ultimately controlled by diffusion. In the absence of water motion, the mathematical description simplifies. The simplest representation of an organism is as a sphere. By calculating the concentrations and material fluxes to and from the sphere, we can understand the world of a cell. The cell's role in this is to remove molecules that reach its surface, transporting them inward.

\section{Diffusion to a sphere}

The fundamental equation describing the concentration $C$ of a substance diffusing with a diffusion coefficient $D$ is given by:

$$
\frac{\partial C}{\partial t}=D \nabla^{2} C
$$

where $t$ is time. If conditions in all directions are the same, the system is spherically symmetric and this reduces to:

$$
\frac{\partial C}{\partial t}=D\left(\frac{\partial^{2} C}{\partial r^{2}}+\frac{2}{r} \frac{\partial C}{\partial r}\right),
$$

where is $r$ is the radial distance from the sphere's center.

For simplicity, we shall assume this spherical symmetry case in subsequent calculations. Dusenbery (Dusenbery, 2009) has an extensive discussion of the effect of non-spherical shapes on uptake. The solution depends on the initial distribution of the substance and the distribution of any sources and sinks.

Steady state

For a sphere centered at the origin, having radius $a$ and concentration at its surface $C(a)$, sitting in a solution with background concentration $C_{0}$, and at steady state $(\partial C / \partial t=0)$ :

$$
C=C_{0}-\frac{a}{r} \Delta C,
$$

where $\Delta C=C_{0}-C(a)$. If the sphere is a cell that is very efficient at removing the substance, the concentration at its surface is effectively 0 and $\Delta C=C_{0}$. The concentration change from the background is half that at the sphere surface at a distance from the center $r=2 a$, which is also a distance $a$ from the cell surface. The conclusion is that the region of greatest change in concentration is localized close to the sphere.

The flux is the flow of material through a unit area and is given by:

$$
\begin{aligned}
\text { flux } & =-D \nabla C \\
& =-D \frac{\partial C}{\partial r} \text { for spherical symmetry } \\
& =\frac{a}{r^{2}} D \Delta C \text { for a sphere at steady state. }
\end{aligned}
$$

The flux is negative if it is toward the sphere and positive if away. The total flow to the surface of a sphere $F$ represents the uptake by the sphere. It equals the flux at the surface multiplied by the surface area of the sphere:

$$
F=4 \pi a^{2}\left(-D \frac{\partial C(a)}{\partial r}\right)=4 \pi a D \Delta C,
$$

when the flow is at steady state.

This relationship is used to describe nutrient uptake by an isolated cell. It states that in the absence of motion and at steady state, diffusion controls the maximum rate at which molecules can approach a cell. By contrast, there is no upper limit on the rate at which material can diffuse away from a cell, if the concentration next to the cell is not constrained.

Non-steady state intake

A relatively simple problem is one in which the sphere suddenly appears in the middle of a solution with uniform solute concentration $C_{0}$. A biological example would be a grazer leaving a region with depleted bacterial concentrations to move to one with an untouched population. Before the region around the cell becomes depleted, the concentration of molecules next to the cell is higher and the flux is temporarily greater.

If again the concentration at the sphere surface $C(a)=0$, then:

$$
C(r, t)=\frac{a C_{0}}{r} \operatorname{erfc}\left(\frac{r-a}{2 \sqrt{D t}}\right),
$$

where erfc is the complementary error function (Visser and Kiørboe, 2006). The gradient at the surface of the sphere is:

$$
\frac{\partial C(r=a)}{\partial r}=-\frac{C_{0}}{\sqrt{\pi D t}}-\frac{C_{0}}{a} .
$$

When the sphere first appears, there is a large initial flux to the surface, which decreases in time to the steady-state value. This model has been used to describe the feeding rate of an ambush feeder (Visser and Kiørboe, 2006). 
Instantaneous release at a point

An even simpler problem can be used to describe the dissipating cloud when a cell lyses, spewing its internal contents into a dissipating spherical cloud. Blackburn and colleagues (Blackburn et al., 1998) have suggested that such ephemeral sources attract bacteria to the higher food concentration. Describing this as an instantaneous release of an amount $M$ of material diffusing radially with a diffusion coefficient $D$, the concentration is then:

$$
C=\frac{M}{(4 \pi D t)^{1.5}} e^{-r^{2} / 4 D t},
$$

where $t$ is time since the release and $r$ is the distance to the point of release. If we choose a reference concentration $C_{\mathrm{r}}$ that defines the boundary of the detection region and $R$ is the radial distance to the boundary, then:

$$
R=\left(4 D t \ln \left(\frac{M}{C_{\mathrm{r}}(4 \pi D t)^{1.5}}\right)\right)^{0.5} .
$$

The time until the cloud dissipates is then $T_{\mathrm{D}}$ :

$$
T_{\mathrm{D}}=\frac{1}{4 \pi D}\left(\frac{M}{C_{\mathrm{r}}}\right)^{2 / 3} \text {. }
$$

\section{Diffusion with microbial uptake}

One important situation is the extent of the molecular cloud around a leaking cell or aggregate. The material being leaked could serve as a desirable substrate for bacteria or phytoplankton. The presence of the bacteria taking the material up should reduce the extent of the cloud around the source. If the rate of uptake is proportional to the substrate concentration and a constant bacterial concentration, we can represent the effect as a loss rate $-k C$, where $k$ is a rate constant.

Addition of this loss to the diffusion equation (Eqn A1) yields:

$$
\frac{\partial C}{\partial t}=D \nabla^{2} C-k C
$$

The solution to this is:

$$
C=C^{\prime} e^{-k t},
$$

where $C^{\prime}$ is the solution to Eqn A1. This solution has been used to describe the fate of nutrients released at a point and dispersed bacteria.

Steady-state diffusion in the presence of microbial uptake For the steady-state spherical system, the differential equation simplifies to:

$$
\left(\frac{\mathrm{d}^{2} C}{\mathrm{~d} r^{2}}+\frac{2}{r} \frac{\mathrm{d} C}{\mathrm{~d} r}\right)-\frac{k}{D} C=0 .
$$

If the concentration goes to 0 as $r \rightarrow \infty$, the solution is:

$$
C=C^{\prime \prime} r^{-1} e^{-\sqrt{k / D} r},
$$

where $C^{\prime \prime}$ is a constant. That is, the solution is the familiar $r^{-1}$ modified by an exponential decrease with distance.

Instantaneous release at a point in the presence of microbial uptake The concentration is modified by the addition of an exponential decay term to Eqn A8:

$$
C=\frac{M}{(4 \pi D t)^{1.5}} e^{-r^{2} / 4 D t} e^{-k t},
$$

where $t$ is time since the release and $r$ is the distance to the point of release. For a given $C_{\mathrm{r}}$ determining the boundary of the detection region and radial distance $R$ to the boundary:

$$
R=\left(4 D t\left(\ln \left(\frac{M}{C_{\mathrm{r}}(4 \pi D t)^{1.5}}\right)-k t\right)\right)^{0.5} .
$$

The dissipation time $T_{\mathrm{D}}$ satisfies the equation:

$$
0=\ln \left(\frac{M}{C_{\mathrm{r}}\left(4 \pi D T_{\mathrm{D}}\right)^{1.5}}\right)-k T_{\mathrm{D}} .
$$

\section{Concentration in wake of a moving point source}

A moving cell can leave a trail, or plume, of anything it is leaking or consuming. The simplest analysis of this situation focuses on the movement and ignores the complexity of flow around the sphere. If it moves in a straight line and acts as a very tiny (point) source, then the diffusion rate along its path is negligible compared with diffusion along its path because concentration gradients are greater perpendicular to the path. The resulting differential equation is the same as for cylindrical diffusion (Okubo, 1980). We can use an equation of the concentration distribution to calculate different plume properties that may be of ecological interest. One of the situations involves the decrease associated with microbes sitting in the plume.

No uptake

The concentration enhancement $C$ as a function of velocity $v$, diffusion coefficient $D$, emission rate $L$, distance $z$ from the source along the path and distance from centerline $\rho$ (e.g. Jackson and Kiørboe, 2004) is described by:

$$
\frac{\partial C}{\partial t}=v \frac{\partial C}{\partial z}=D\left(\frac{1}{\rho} \frac{\partial C}{\partial \rho}+\frac{\partial^{2} C}{\partial \rho^{2}}\right),
$$

whose solution is:

$$
C=\frac{L}{4 \pi D z} e^{-\frac{v \rho^{2}}{4 D z}},
$$

where the distance to the plume is $\rho=\left(x^{2}+y^{2}\right)^{0.5}$ and the object moves along $x=y=0$. This equation describes a plume that extends to infinity. Biologically, we expect that there is a practical limit determined by a minimum concentration change. If we choose a reference concentration $C_{\mathrm{r}}$ that defines the boundary, we can calculate a plume length $Z_{0}$, plume radius $\rho_{0}^{*}$ at $z<Z_{0}$, and plume volume $V_{0}$ :

$$
\begin{aligned}
& Z_{0}=\frac{L}{4 \pi D C_{\mathrm{r}}}, \\
& \rho_{0}^{*}=\left(\frac{4 D z}{v}\right)^{0.5}\left(\ln \frac{Z_{0}}{z}\right)^{0.5}=\left(\frac{4 D z}{v}\right)^{0.5}\left(\ln \frac{L}{4 \pi D C_{\mathrm{r}} z}\right)^{0.5}, \\
& V_{0}=\int_{0}^{Z_{0}} \pi \rho_{0}^{* 2} \mathrm{~d} z=\frac{\pi D Z_{0}^{2}}{v}=\frac{L^{2}}{16 \pi C_{\mathrm{r}}^{2} D v} .
\end{aligned}
$$

The cross-sectional area of this plume $\sigma_{0}$, as seen perpendicular to the source path, is:

$$
\sigma_{0}=\int_{0}^{Z_{0}} 2 \rho_{0}^{*} \mathrm{~d} z=4\left(\frac{2 \pi D}{27 v}\right)^{0.5} Z_{0}^{1.5}=\frac{1}{3 \pi D}\left(\frac{L^{3}}{6 v C_{\mathrm{r}}^{3}}\right)^{0.5} .
$$


The length of time that a plume lasts $T_{0}$ is given by:

$$
T_{0}=\frac{Z_{0}}{v}=\frac{L}{4 \pi D C_{\mathrm{r}}} .
$$

With microbial uptake

To incorporate a uniformly distributed sink, we add a term $-k C$ to Eqn A18, just as in Eqn A11. The result is that of Eqn A19 with an added exponential decay term:

$$
C=\frac{L}{4 \pi D z} e^{-\frac{v \rho^{2}}{4 D z}} e^{-k z / v} .
$$

The equations in the presence of uptake for plume length $Z_{1}$, width $\rho_{1}^{*}$, and volume $V_{1}$ need to be modified from the $Z_{0}, \rho_{0}^{*}$ and $V_{0}$ forms:

$$
\begin{gathered}
Z_{1} e^{k Z_{1} / v}=\frac{L}{4 \pi D C_{\mathrm{r}}}, \\
\rho_{1}^{*}=\left(\frac{4 D z}{v}\right)^{0.5}\left(\ln \frac{L}{4 \pi D C_{\mathrm{r}} z}-\frac{k z}{v}\right)^{0.5} \\
=\left(\frac{4 D z}{v}\right)^{0.5}\left(\ln \frac{Z_{1}}{z}+\frac{k Z_{1}}{v}\left(1-\frac{z}{Z_{1}}\right)\right)^{0.5}, \\
V_{1}=\int_{0}^{Z_{1}} \frac{4 \pi D z}{v}\left(\ln \frac{Z_{1}}{z}+\frac{k Z_{1}}{v}\left(1-\frac{z}{Z_{1}}\right)\right) \mathrm{d} z \\
=\frac{\pi D Z_{1}^{2}}{v}\left(1+\frac{2 k Z_{1}}{3 v}\right) .
\end{gathered}
$$

Note that Eqn A26 does not have a closed form solution and needs to be solved numerically.

\section{Concentration in the wake of a moving disk}

An animal swimming in search of food sweeps out an area in front of it whose size depends on the distance at which the animal can sense its prey. As it feeds, it leaves behind it a tube emptied of prey, which ultimately fills refills with prey. For a prey species that moves in random walks, changes in its concentration can be described as diffusion, in a situation similar to that of the plume created by a moving point source or sink. In this case, the moving point sink is modified to be a moving disk of radius $P$, which represents the predator's sensory distance. While the mathematics are similar for a source and a sink, we will consider the situation of a sink, with a prey concentration of 0 in a moving disk that represents the feeding zone.

We use the same approach as in the previous section, when calculating the profile of a point plume, assuming that this is really a 2-dimensional problem in which $t=z / v$. If we assume that the plume extends to the region where the concentration is half the background concentration, then we can calculate a plume halfwidth $\rho_{2}$ along the path, a plume length $Z_{2}$ and a time $T_{2}$. The complete solution to this is given in p. 260 (X-VII) of Carslaw and Jaeger (Carslaw and Jaeger, 1959).

For $\rho_{1 / 2}(z)$, for a critter swimming along the $z$-axis, the solution satisfies the equation:

$$
0=-\frac{1}{2}+\left(\frac{v}{2 D z}\right) e^{-\rho_{2}^{2} v /(4 D z)} \int_{0}^{P} I_{0}\left(\frac{\rho_{2} \rho v}{2 D z}\right) e^{-\rho^{2} v /(4 D z)} \rho \mathrm{d} \rho,
$$

where $I_{0}$ is a modified Bessel function of the first kind. This can be solved numerically for $\rho_{2}$, as well as for the value of $\rho$ associated with any other threshold concentration (Fig. A1).

The length of the plume is given more simply [see eqn 13 on p. 260 of Carslaw and Jaeger (Carslaw and Jaeger, 1959)]. The concentration along the plume is:

$$
\frac{C}{C_{0}}=1-e^{-\rho_{2}^{2} / 4 D t} .
$$

The disappearance time, $T_{2}$, is given by:

$$
T_{2}=\frac{P^{2}}{4 D \ln 2} .
$$

The length of the plume is then:

$$
Z_{2}=v T_{2}=\frac{v P}{4 D \ln 2} .
$$

Similarly, the volume affected can be calculated as in Eqn A22 (Fig. A1).

\section{Effect of motion on transport}

Swimming by an organism or other fluid motions can overcome the transport limitation imposed by diffusion. In some cases, the organism is able to swim fast enough to reach new material faster than diffusion alone can supply it. In addition, external fluid motions driven by turbulence can distort the depleted regions trailing a swimming organism, twisting them and breaking them into pieces.

\section{Parameterization of fluxes}

The relative importance of organism movement relative to diffusion in supplying nutrients can be expressed using the Péclet number:

$$
\mathrm{Pe}=\frac{v L}{D}
$$

where $L$ is a characteristic length of the organism, often chosen to be the diameter. Movement has little effect on the total rate at which
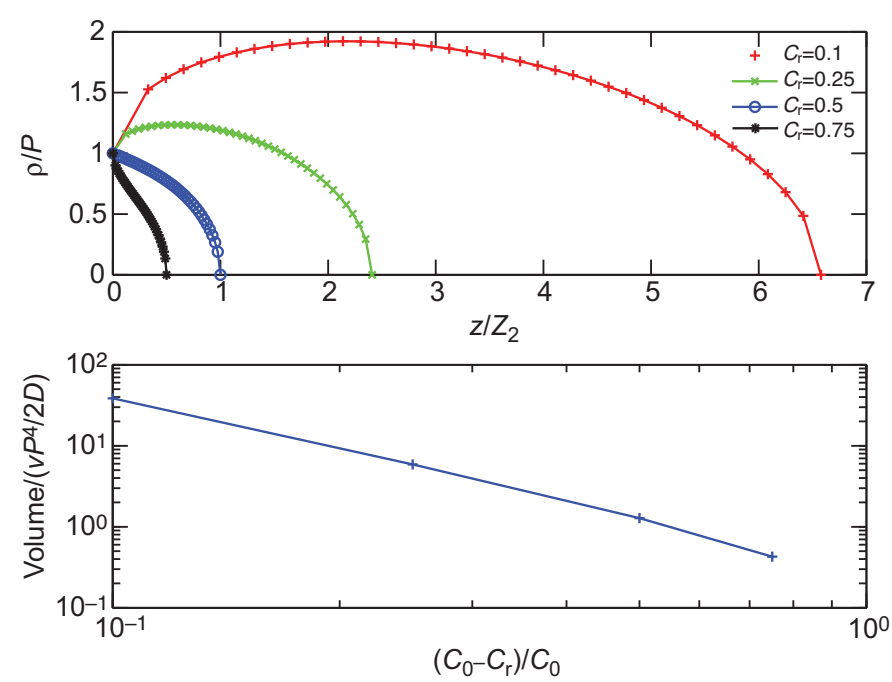

Fig. A1. Depletion plume behind a particle clearer with a finite size crosssection. Top: plume width as a function of distance, with plume width normalized to the disk radius $(P)$ and the distance down the plume normalized to $Z_{2}$, the length of the plume defined by the concentration boundary equal to half the background. Bottom: normalized plume volume as a function of the plume boundary concentration $C$. 
material comes to an object when $\mathrm{Pe}<1$. The supply rate of material from solution to a spherical organism as a result of both water motions and diffusion relative to that from diffusion alone is described using the Sherwood number:

$$
\mathrm{Sh}=\text { uptake } /(4 \pi D a \Delta C),
$$

where $a$ is still the organism radius. Sh is 1 when there is no flux enhancement. Sh can be expressed as a function of Pe (e.g. Clift et al., 1978).

\section{Parameterization of plume metrics}

Visser and Jackson (Visser and Jackson, 2004) examined the effect of turbulence on various metrics of a plume, such as that formed by a leaky swimming animal or a falling marine snow particle. Turbulence had multiple effects on the plume, including stretching and breaking it into pieces as well as wrapping it up into a more compact ball. Such concepts as plume length needed to be altered to distinguish between total length along the plume, the plume length to first break, and extension distance in one direction. The crucial parameter describing the effect of turbulence on the plume is $\gamma T_{0}$, where $\gamma$ is the average turbulent shear rate and $T_{0}=Z_{0} / v$ is the length of time the plume lasts in the absence of turbulence (Eqn A24). For further discussion, see Visser and Jackson (Visser and Jackson, 2004).

\section{Animal feeding}

Animal feeding involves both the depletion of food in the region around an animal and the enhancement of nutrient concentration as food is metabolized and released back into the environment. Animal movement determines the geometry of the regions of depletion and enhancement associated with the animal.

The organic compounds supplying microbial growth have a variety of sources, including leakage from algae, excretion by animals and degradation of particles. While some of these sources are small and sedentary, others move through the water, potentially leaving behind a chemical trail in the form of a higher dissolved nutrient concentration plume. Such a plume creates a finite-sized environment that can be used as a food resource by a microbe or as a sensory trail for a predator. The size of a sensory plume depends on, among other factors, the sensitivity with which the concentration can be detected.

The fastest way for an animal to find food is to swim in a straight line (Visser and Kiørboe, 2006), but this can also be the fastest way to be eaten. How do animals address this dilemma? Bigger animals tend to sense larger distances $(R)$ than the straight paths of their prey. If a small prey moves in a straight line for a 'short' distance $l$, then turns, its larger scale movements are effectively diffusive on the scale at which the larger predators work, but it effectively feeds itself as if moving in a straight line hunting for smaller prey. Random motion like this leads to diffusive behavior, described by diffusion coefficients. What allows this strategy to work is that aquatic food chains tend to be size based, with organisms eating prey 1/10 their size (e.g. Fenchel, 1987).

Fenchel (Fenchel, 1987) and Okubo (Okubo, 1987) showed that swimming velocity scales approximately with body length. Visser and Kiørboe (Visser and Kiørboe, 2006) showed that the mean run length $\lambda$ is also proportional to length and the mean run time is relatively constant. This implies that the diffusion should scale as $v^{2}$, or about $d^{2}$. Visser and Kiørboe (Visser and Kiørboe, 2006) observed something close:

$$
D=\alpha_{1} d^{\lambda_{1}}
$$

where $\alpha_{1}=2.8 \mathrm{~cm}^{0.29} \mathrm{~s}^{-1}$ and $\lambda_{1}=1.71$. Note that there are a large number of relationships between organism diameter and another property of the form $\alpha d^{\lambda}$. They are distinguished from each other here by their subscripts. For example, organism swimming velocity as a function of body length $d$ is:

$$
v=\alpha_{2} d^{\lambda_{2}}
$$

where $\alpha_{2}=2.9 \mathrm{~s}^{-1}$ and $\lambda_{2}=1$ (Mauchline, 1998).

The molecular diffusion coefficients are typically of the order of $D=10^{-5} \mathrm{~cm}^{2} \mathrm{~s}^{-1}$. Bacteria swim in different patterns, but typical estimates for the bacterial diffusivity are similar to those for molecular diffusivity, $10^{-6}$ to $10^{-5} \mathrm{~cm}^{2} \mathrm{~s}^{-1}$. Animal diffusivities are larger.

\section{Feeding rates, coagulation kernels}

Feeding rate $\left(F_{\mathrm{p}}\right)$ of an individual of type $\mathrm{p}$ on individuals of type f can be expressed as:

$$
F_{\mathrm{p}}=\beta\left(d_{\mathrm{p}}, d_{\mathrm{f}}\right) C_{\mathrm{f}},
$$

where the symbol $\beta$ is the feeding kernel and is used to highlight the similarity to coagulation theory. It is also known as the clearance rate. The subscripts $\mathrm{p}$ and $\mathrm{f}$ are used to denote quantities for predator and prey (food). As in coagulation theory, we break the feeding into different types.

\section{Feeding by swimming in a straight line}

Feeding rate

An animal swimming in straight line with velocity $v$, catching anything within a sensory radius $R$, sweeps out a cross-sectional area $\pi R^{2}$. The feeding kernel $\beta_{\mathrm{sw}}$ is given by:

$$
\beta_{\mathrm{sw}}=v \pi R^{2}=\pi \alpha_{2} d R^{2} .
$$

Plume cross-section with sensory apparatus

Animals can use chemical plumes to find food or mates. In this case, a finite-sized sensory apparatus can improve the region being searched. If we include the effect of a finite-sized detection width $R$, such as the antenna of a copepod, added to the cross-section $\sigma_{0}$ in Eqn A23, we can calculate an enhanced detection cross-section to the plume:

$$
\sigma^{+}=\sigma_{0}+R Z_{0}=\sigma_{0}+R \frac{L}{4 \pi D C_{0}}
$$

An organism swimming perpendicular to the plume has a feeding kernel:

$$
\beta_{\mathrm{sw}}=v \sigma^{+} \text {. }
$$

This cross-section is similar to a capture cross-section and can be used to calculate the rate at which an animal will encounter plumes. Jackson and Kiørboe have used this approach to calculate the rates at which zooplankton encounter particles as functions of the sizes of both the particles and the animals (Jackson and Kiørboe, 2004).

\section{Depletion and enhancement plumes}

Having searched the region through which it passes, the grazer leaves behind a plume depleted of its prey. If we assume that the prey motions look diffusive on the scale of the grazer's search distance, then we can use diffusion theory to calculate the plume geometry. The grazer will also leave behind a plume of excreted organic matter and inorganic nutrients, in a shape described by 
Eqns A20-23. As noted earlier, turbulent motions are important for larger plumes, as they can distort their shapes (e.g. Visser and Jackson, 2004), but will not be considered further here.

In the absence of turbulent motions, we can estimate the length of an enhancement plume relatively simply from EqnA19 as $Z=$ leakage rate $/\left(4 \pi D C_{\mathrm{r}}\right)$, where $C_{\mathrm{r}}$ is the concentration defining the boundary of the plume. The numerical value of $C_{\mathrm{r}}$ can be chosen as the minimum detectable concentration by the organism trying to detect it (Jackson and Kiørboe, 2004). If we consider a depletion region that is bounded by $C_{\mathrm{r}}=0.5 C_{0}$, then $C_{\mathrm{r}}=\Delta C / 2$, and $Z=2 a \mathrm{Sh}$. When there is no enhancement of nutrient uptake by motion, $\mathrm{Sh}=1$ and $Z=2 a=d$. This is the same result as we had for the pure diffusion case. The addition of a finite sensory width can increase the effective plume width considerably.

\section{Ambush feeders}

Feeding rate

Ambush predators wait for their food to come to them. Swimming animals tend to swim in short straight segments, interspersed with direction changes. When the feeding distance of a stationary predator is large relative to the length of the average straight segment path of its prey, the prey motion looks to be diffusive to the predator. Predicting the rate at which the prey meets the predator becomes the same diffusion problem as that predicting the rate at which a solitary bacterium feeds on diffusing solutes (Eqn A5). The feeding kernel $\beta_{\mathrm{amb}}$ is given by:

$$
\beta_{\mathrm{amb}}=4 \pi R D_{\mathrm{f}}=4 \pi \alpha_{1} d_{\mathrm{f}}^{\lambda_{1}} R,
$$

Depletion and enhancement regions

For small turbulence mixing rates, the geometries of the fooddepleted and excretion-enhanced regions are described simply by the same diffusion problem (Eqn A1). Thus, the same functions apply for both the inward transport of food and the outward transport of regenerated nutrients, although the relative size of the affected areas depends on the relative diffusivity of the two materials.

\section{Run and stop feeders}

When an ambush predator jumps to a new position, there is enhanced feeding because the region nearest to its new position has not yet been depleted of food. Visser and Kiørboe (Visser and Kiørboe, 2006) argue that the feeding rate starts as that of the animal feeding by moving in a straight line and slows to that of the steady-state ambusher:

$$
\begin{aligned}
\beta_{\mathrm{amb}} & =4 \pi D_{\mathrm{f}} R\left(1+\frac{R}{\sqrt{\pi D_{\mathrm{f}} t}}\right) \\
& =4 \pi \alpha_{1} d_{\mathrm{f}}^{\lambda_{1}} R+4\left(\pi \alpha_{1} d_{\mathrm{f}}^{\lambda_{1}}\right)^{0.5} R^{2} t^{-0.5} .
\end{aligned}
$$

That is, there is a short-term burst of feeding when the predator first arrives that decays to the steady-state rate. The length of time that the initial feeding enhancement lasts depends on the sensory range of the predator and the diffusivity of the prey.

Flux feeders, vertical migration

Filter feeding is the classical mode for particle feeders and is akin to search feeding. An alternative mode is for animals to sit in one spot and allow particles to fall on them in what has been called flux feeding (Jackson, 1993). While the kernel is similar to $\beta_{\mathrm{sw}}$, it substitutes the falling speed $v_{\mathrm{s}}$ of the particles for that of the swimming speed of the predator. Ambush feeding on vertically migrating zooplankton also has the form of the search kernel, although with the swimming speed of the prey substituting for that of the predator.

In both cases, they leave a depleted region below that fills in from lateral movement of particles and water behind the predator. While such a predator forms a depletion plume, it forms a purely diffusive excretion plume.

\section{System properties}

Most of these effects of organisms on their environments are extremely dependent on the organism size. Thus, if we are to describe the chemical seascape, we need to account for the sizes and abundances of the different organisms generating it. We use the size distribution to describe the size dependence of organism concentration. We integrate rates of interest over relevant size ranges to find the total effect of organisms of multiple sizes, feeding rates and concentrations. We will integrate over all sizes to determine the net effect on the community properties.

\section{Size distributions}

Given the importance of size in structuring the enhancement or depletion by an organism or other particle, it is important to have an easy way to represent the size dependence of particle concentration. Particle size distributions provide the means. For any small size range $d s$, the concentration of particles between $s$ and $s+d s$ is given by:

$$
d C(s)=n(s) d s,
$$

where $n(s)$ is the number size spectrum in terms of size measure $s$. Particle size can be expressed in many ways, including mass, nitrogen content and radius. For the present purposes, it is convenient to work with the size spectrum in terms of diameter $d$.

For any object property that is associated with size, we can easily calculate the total concentration associated with particles in a given size range. For example, if $m(d)$ is the mass of an object with diameter $d$, then the mass concentration $M$ contained in particles between $d_{1}$ and $d_{\mathrm{u}}$ is:

$$
M=\int_{d_{1}}^{d_{u}} m(d) n(d) \mathrm{d} d .
$$

\section{Size distributions of animals}

Rodriguez and Mullin (Rodriguez and Mullin, 1986) discussed size distributions of animals as a function of size. They first measured the relationship between zooplankton biomass and length, which we assume is equivalent to diameter. They described their results with a power relationship:

$$
m=\alpha_{3} d^{\lambda_{3}},
$$

where $\alpha_{3}=2.63 \times 10^{-6} \mu \mathrm{g} \mathrm{C}_{\mu \mathrm{m}^{-2.23}}\left(=2.8 \times 10^{-5} \mathrm{~mol} \mathrm{~N} \mathrm{~cm}^{-2.23}\right.$ for an assumed $\mathrm{C}: \mathrm{N}=6.6$ ) and $\lambda_{3}=2.23$. They then calculated a normalized biomass spectrum of the form:

$$
m n(m)=m n(d) \frac{\mathrm{d} d}{\mathrm{~d} m}=a_{1} m^{b_{1}},
$$

where $n(m)$ is the number spectrum on a mass basis $\left(\mu \mathrm{g}^{-1} \mathrm{Ccm}^{-3}\right)$ and $n(d)$ is the number spectrum on a diameter basis $\left(\mathrm{cm}^{-4}\right)$. They calculated average values of $a_{1}=1.10 \times 10^{-4} \mu \mathrm{g} \mathrm{C}^{1.16} \mathrm{~cm}^{-3}$ and $b_{1}=-1.16$ for samples from the North Pacific Central Gyre.

This is equivalent to:

$$
n(d)=\alpha_{4} d^{\lambda 4},
$$


where $\alpha_{4}=a_{1} \lambda_{3}^{-1} \alpha_{3}^{b_{1}}$ and $\lambda_{4}=b_{1} \lambda_{3}-1$. For the above case (Rodriguez and Mullin, 1986) in the North Pacific Central Gyre, $\alpha_{4}=3.28 \times 10^{-8} \mathrm{~cm}^{-0.41}$ and $\lambda_{4}=-3.59$.

\section{Size distributions of aggregates}

Non-organism particles have also been sampled extensively and their distributions fitted to relationships of the form Eqn A47, with values of $\lambda_{4}$ from -2 to -6 (e.g. Sheldon et al., 1972; Guidi et al., 2009). While Eqn A47 is a useful way to summarize a size distribution, it can over-represent the abundance of the largest particles (Jackson and Checkley, 2011).

\section{Other scaling relationships}

Metabolic rates

Huntley and Boyd (Huntley and Boyd, 1984) argued that the respiration rate varied with temperature but scaled as a function of animal mass

$$
Q=a_{2} m^{b_{2}}=\alpha_{5} d^{\lambda 5},
$$

for a temperature of $20^{\circ} \mathrm{C}$ and for their carbon to dry mass value $(=0.4)$, where $a_{2}=4.8 \times 10^{-6} \mu \mathrm{g} \quad \mathrm{C}^{0.31} \mathrm{~s}^{-1}, \quad b_{2}=0.69, \quad \alpha_{5}=a_{2} \alpha_{3}^{b 2}=$ $6.75 \times 10^{-10} \mu \mathrm{g} \mathrm{Cs}^{-1} \mu \mathrm{m}^{-1.54}\left(=1.23 \times 10^{-11} \mathrm{~mol} \mathrm{~N} \mathrm{~s} \mathrm{~cm}^{-1.54}\right.$, again for $\mathrm{C}: \mathrm{N}=6.6)$ and $\lambda_{5}=b_{2} \lambda_{3}=1.54$. Other useful relationships include size-dependent rates of $\mathrm{CO}_{2}$ respiration for zooplankton (Mayzaud et al., 2005) and zooplankton grazing rates as a function of organism size (Hansen et al., 1997).

\section{Acknowledgements}

This work has been inspired by and benefited from conversations with Andy Visser and Thomas Kiørboe of the Danish Technical University. Mark Denny and Thomas Kiørboe provided useful feedback on a draft version of this manuscript. Bess Ward noted the preponderance of non-motile microbes in the ocean.

\section{Funding}

This work was supported by the National Science Foundation (NSF) [grant OCE03-52127].

\section{References}

Bearon, R. N. and Grünbaum, D. (2008). From individual behaviour to population models: a case study using swimming algae. J. Theor. Biol. 251, 679-697.

Benoit-Bird, K. J. (2009). Dynamic 3-dimensional structure of thin zooplankton layers is impacted by foraging fish. Mar. Ecol. Prog. Ser. 396, 61-76.

Berg, H. C. (1983). Random Walks in Biology. Princeton: Princeton University Press.

Blackburn, N., Fenchel, T. and Mitchell, J. (1998). Microscale nutrient patches in planktonic habitats shownby chemotactic bacteria. Science 282, 2254-2256.

Carslaw, H. S. and Jaeger, J. C. (1959). Conduction of Heat in Solids. Oxford: Clarendon Press.

Clift, R., Grace, J. R. and Weber, M. E. (1978). Bubbles, Drops and Particles. New York: Academic Press.

Crank, J. (1975). The Mathematics of Diffusion, 2nd edn. Oxford: Oxford Scientific.

Dusenbery, D. B. (2009). Living at Microscale. Cambridge: Harvard University Press.
Fenchel, T. (1984). Suspended bacteria as a food source. In Flows of Energy and Materials in Marine Ecosystems (ed. M. J. R. Fasham), pp. 301-315. New York: Plenum Press.

Fenchel, T. (1987). Ecology of Protozoa. Berlin: Springer-Verlag.

Fukuda, R., Ogawa, H., Nagata, T. and Koike, I. (1998). Direct determination of carbon and nitrogen contents of natural bacterial assemblages in marine environments. Appl. Environ. Microbiol. 64, 3352-3358.

Gerritsen, J. and Strickler, J. R. (1977). Encounter probabilities and community structure in zooplankton: a mathematical model. J. Fish. Res. Board Can. 34, 73-82.

Guidi, L., Stemmann, L., Jackson, G. A., Ibanez, F., Claustre, H., Legendre, L., Picheral, M. and Gorsky, G. (2009). Effects of phytoplankton community on production, size and export of large aggregates: a world-ocean analysis. Limnol. Oceanogr. 54, 1951-1963.

Hansen, P. J., Bjørnsen, P. K. and Hansen, B. (1997). Zooplankton grazing and growth: scaling within the $2-2,000 \mu \mathrm{m}$ body size range. Limnol. Oceanogr. 42, 687704.

Huntley, M. and Boyd, C. (1984). Food-limited growth of marine zooplankton. Am. Nat. 124, 455-478.

Jackson, G. A. (1980). Phytoplankton growth and zooplankton grazing in oligotrophic oceans. Nature 284, 439-441.

Jackson, G. A. (1987). Physical and chemical properties of aquatic environments. In Ecology of Microbial Communities (ed. M. Fletcher, T. R. G. Gray and J. G. Jones), pp. 213-233. Cambridge: Cambridge University Press.

Jackson, G. A. (1993). Flux feeding as a mechanism for zooplankton grazing and its implications for vertical particulate flux. Limnol. Oceanogr. 38, 1328-1331.

Jackson, G. A. and Checkley, D. M., Jr (2011). Particle size distributions in the upper $100 \mathrm{~m}$ water column and their implications for animal feeding in the plankton. Deep Sea Res. I 58, 283-287.

Jackson, G. A. and Kiørboe, T. (2004). Zooplankton use of chemodetection to find and eat particles. Mar. Ecol. Prog. Ser. 269, 153-162.

Kiørboe, T. (2008). A Mechanistic Approach to Plankton Ecology. Princeton: Princeton University Press.

Kiørboe, T. and Jackson, G. A. (2001). Marine snow, organic solute plumes, and optimal chemosensory behavior of bacteria. Limnol. Oceanogr. 46, 1309-1318.

Leal, L. G. (1992). Laminar Flow and Convective Transport Processes. Boston: Butterworth-Heinemann.

Lehman, J. T. and Scavia, D. (1982). Microscale patchiness of nutrients in plankton communities. Science 216, 729-730.

Mauchline, J. (1998). The Biology of Calanoid Copepods. San Diego: Academic Press.

Mayzaud, P., Boutoute, M., Gasparini, S. and Mousseau, L. (2005). Respiration in marine zooplankton - the other side of the coin: $\mathrm{CO}_{2}$ production. Limnol. Oceanogr. 50, 291-298.

McCarthy, J. J. and Goldman, J. C. (1979). Nitrogen nutrition of marine phytoplankton in nutrient depleted waters. Science 203, 670-672.

Mullin, M. M., Sloan, P. R. and Eppley, R. W. (1966). Relationships between carbon content, cell volume, and area in phytoplankton. Limnol. Oceanogr. 11, 307-311.

Munk, W. H. and Riley, G. A. (1952). Absorption of nutrients by aquatic plants. J. Mar. Res. 11, 215-240.

Okubo, A. (1980). Diffusion and Ecological Problems: Mathematical Models. Berlin Springer-Verlag.

Okubo, A. (1987). Fantastic voyage into the deep: marine biofluid mechanics. In Mathematical Topics in Population Biology, Morphogenesis, and Neurosciences (ed E. Teremoto and M. Yamaguti), pp. 32-47. New York: Springer-Verlag.

Rodriguez, J. and Mullin, M. M. (1986). Relation between biomass and body weight of plankton in a steady state oceanic ecosystem. Limnol. Oceanogr. 31, 361-370.

Rothschild, B. J. and Osborn, T. R. (1988). Small-scale turbulence and plankton contact rates. J. Plankton Res. 10, 465-474.

Saiz, E. and Kiørboe, T. (1995). Predatory and suspension feeding of the copepod Arcartia tonsa in turbulent environments. Mar. Ecol. Prog. Ser. 122, 147-158.

Sheldon, R. W., Prakash, A. and Sutcliff, W. H. (1972). Size distribution of particles in the ocean. Limnol. Oceanogr. 17, 327-340.

Smoluchowski, M. (1917). Versuch einer matehmatischen Theorie der Koagulationskineti kolloider Lsungen. Z. Physik. Chem. 92, 129-168.

Visser, A. W. and Jackson, G. A. (2004). Characteristics of the chemical plume behind a sinking particle in a turbulent water column. Mar. Ecol. Prog. Ser. 283, 55-71.

Visser, A. W. and Kiørboe, T. (2006). Plankton motility patterns and encounter rates. Oecologia 148, 538-546. 